\title{
Effects of Word-of-mouth WOM \\ On Donators' Relationship with \\ CSOs in Egypt after 2013
}

Amany Hassan Bassyouny, PhD*

\section{Introduction}

The word of mouth (WOM) has been recognized as a crucial marketing technique in the past two decades, although it dates back to ancient history and pre-media existence eras. This industry is experiencing massive growth, which is particularly evident in online and social networking media. Word-of-mouth (WOM) marketing has recently attracted a great deal of attention among practitioners. Misner calls it "the world's most effective, yet least understood marketing strategy" $\left({ }^{1}\right)$. Marketers are particularly interested in better understanding word-of-mouth as traditional forms of communication appear to be losing effectiveness.

This research paper aims to explore the effects of WOM on the relationship between donators and Civil Society Organizations (CSOs) in Egypt after 2013. CSOs have played a distinct role in the Egyptian society since the end of the $19^{\text {th }}$ century. With the number of CSOs exceeding 48,750 organizations and their beneficiaries counted by millions of Egyptians $\left({ }^{2}\right)$, the role of such organizations in the Egyptian social and political life has been magnified in the past five decades. Donations from individuals and entrepreneurs have been the main source of funding for such CSOs, which suffered a crisis of lack of donations after the 2013 changes of the political regimes.

As a communication and public relations scholar, the researcher was particularly interested in the way negative word-of-mouth NWOM affected the reputation and credibility of certain popular CSOs in Egypt. Image and reputation are considered the key assets for such

\footnotetext{
* Amany Hassan Bassyouny, assistant professor of IMC, acting head of mass communication department, Faculty of Alsun and Mass Communication at Misr International University MIU, Egypt.
} 
organizations that guarantee the flow of donations and positive responses to their fund-raising campaigns. This research paper aims to examine the effect of word-of-mouth (WOM) on the relationship between private, local donators and local CSOs in Egypt after 2013.

Using the WOM model, an empirical study, using an online survey and a non-probability sample, has been conducted to explore the individual donators' attitudes towards CSOs and the effect of WOM on their donation behavior in Egypt after 2013.

The paper is structured as follows: first the significance of the study is explained and this is followed by a review of the relevant literature that provides an appropriate background for it. Next, the proposed model is presented and the research questions are explained together with the rationale. Third, the methodology used to empirically test the model is detailed, and the results described. Fourth, the implications of the findings for both theory and practice are discussed, while recognizing important limitations. In closing, some future research directions are suggested.

\section{Significance of the Study:}

The importance of this study lies in its attempt to explore the effect of WOM on Egyptian individual donators regarding their attitude and donation behavior towards local CSOs. This communication study has both an academic significance and a practical value as we lack similar studies of WOM in the Arab empirical studies' literature. It has a practical significance as the drop-of donations' crisis that resulted from NWOM caused numerous local Egyptian CSOs to declare a crisis situation that lead them to hire professional marketing and communication agencies to defend their images and regain a good reputation as the CSOs realized the direct relationship between the loss-of- donations and the value of public relations in monitoring and defending their reputation.

\section{Literature Review}

This study is concerned with examining the nature of word-of-mouth as a communication process and its relation to the donation behavior 
of Egyptian educated citizens towards local Civil Society institutions in Egypt. Accordingly, the review of previous studies will focus on defining WOM, its related studies and reviewing the literature of CSOs communication-related studies.

Word-of-mouth: The term WOM refers to oral or written recommendation by a satisfied customer to the prospective customers of a good or service. Considered to be the most effective form of promotion, it is also called word of mouth advertising which is incorrect because, by definition, advertising is a paid and non-personal communication. Researches rated WOM as nine times more effective in making people switch from unfavorable or neutral attitudes to favorable ones compared to advertising. $\left({ }^{3}\right)$ Numerous studies confirmed that WOM has more influence than any other communication channel. $\left({ }^{4}\right)$ A recent study suggests that the public's perception of relational satisfaction with the organization has an impact on supportive behaviors toward the organization. $\left({ }^{5}\right)$

Research on WOM behavioral effects focused on various aspects of WOM, like when word-of-mouth may have a larger impact on behavior and why. One important factor is characteristics of the wordof-mouth source. People tend to listen more to credible sources, or those that are more trustworthy or have more expertise. Other important factors are the strength of the tie (i.e., friends vs. acquaintances, or strong vs. weak ties) and their similarity to the word-of-mouth recipient. Instance of word-of-mouth, strong ties may be more impactful because people tend to trust them more and think they know more about their tastes and interests. Similarly, word-ofmouth from similar others may have a more positive effect. $\left({ }^{6}\right)$ Finally, heavy users of internet seem to have a larger impact in social spheres, but it is unclear whether this is because they talk more frequently or because they have higher status and is thus more likely to be listened to. Another important factor is the nature of the wordof-mouth itself. Word-of-mouth varies in its valence. Recommendations likely have the most positive impact on behavior, but even mentions should have a positive effect if they increase product awareness or accessibility. In terms of absolute impact, negative word-of-mouth may have a stronger impact than positive 
word-of-mouth, in some cases $\left(^{7}\right)$. It may be more impactful when the word-of-mouth event happened further in the past. Word-of-mouth also varies in its intensity or depth: People can talk briefly about an experience or they can go on at length. Longer or more in-depth wordof-mouth discussions should have a stronger impact on behavior. Along these lines, face-to-face word-of-mouth may have a stronger impact than online or written word-of-mouth because it tends to be more engaging and vivid. Whether the word-of-mouth is solicited also matters. Solicited advice seems to have a more positive impact than unsolicited advice. Finally, the level of certainty expressed along with an opinion can also have an effect. The susceptibility of the word-ofmouth recipient is also important. Some people may be more susceptible to, or prone to be affected by, social influence $\left({ }^{8}\right)$. People who perceive themselves as opinion leaders are less susceptible. The closer people already are to taking some action, the more likely it is that a dose of word-of-mouth will push them over the edge.

EWOM is defined as "any positive or negative statement made by potential, actual, or former customers about a product or company, which is made available to a multitude of people and institutions via the Internet" $\left({ }^{9}\right)$.

The utility of social media sites lies in their influence over certain demographics (e.g., teens and young adults) that have migrated from more traditional mass media such as newspapers and television $\left({ }^{10}\right)$. At the same time, social media sites serve as an exclusive platform for consumers to publicize their evaluations of purchased products, thus facilitating word-of-mouth (WOM) communication $\left({ }^{11}\right)$ and influencing such key elements of the company-consumer relationship as brand image and brand awareness $\left({ }^{12}\right)$.

The interactive feature of the internet created a platform of freedom of expression in Egypt in the areas of fighting corruption, political awareness and participation, and defending human rights. $\left({ }^{13}\right)$ Formal statistics indicate that internet users in Egypt reached 50 million in April 2016, 25 million of which use facebook and Youtube. $\left({ }^{14}\right)$

Many researchers explored the value of online WOM in the booming era of the internet. Studies revealed that higher number of reviews 
lead to higher relative sales and longer lasting effects than traditional marketing activities $\left({ }^{15}\right)$.

Civil Society Organizations (CSOs) in Egypt:

Civil society refers to the arena of unforced collective action around shared interests, purposes, and values. Civil societies often include organizations such as registered charities, development nongovernmental organizations, community groups, women's organizations, faith-based entities, professional associations, trade unions, youth-centers, coalitions, and advocacy groups. $\left({ }^{16}\right)$

The literature about the relationship between CSOs and big, international funding agencies emphasized that it is more a patronclient relationship that deprives local CSOs from freedom to allocate donations to the needs of the poor communities $\left({ }^{17}\right)$. Many researchers also concluded the funders' unawareness and lack of understanding of cultural context and local voices, funding organizations' focus on reports for advocacy purposes that will lead to empowerment of certain local groups, lead to more tension between those CSOs and the funders. $\left({ }^{18}\right)$

The classification of civil society organizations suggests two main types, the 'Narrow gap' organizations and the 'Wide gap' ones. The Narrow gap organizations are characterized by a majority of core funding, an advocacy focus, organizational cultures that emphasize research and policy and are oriented to niche audiences. Wide gap organizations, by contrast, are more reliant on project funding, focus mostly on relief work in local communities, have organizational cultures that emphasize marketing and outreach and seek to reach broad, general audiences $\left({ }^{19}\right)$. Egyptian studies identified human rights organizations in Egypt to follow the first type $\left({ }^{20}\right)$. Egyptian CSOs that fall under local development sector in Egypt can be identified as Wide gap organizations.

This classification created two distinct publics; niche, elite public involved in debating complex issues for narrow gap CSOs addressed mainly through conferences, symposiums, sophisticated publications and elite news media and a broad, general public for Wide gap 
organizations addressed as a potential donor through general news media.

The wide gap organizations with their dependence on the donations of broad, general audience in Egypt are the main focus of this study that tends to explore the role of WOM in damaging the relationship between CSOs and the Egyptian donators. The foundation of civil society is the public. Civil society is based upon an informed and empowered public. In a civil society, the public has the right and the desire to participate in local, regional, and national decisions. $\left({ }^{21}\right)$

Media outlets have the potential to perform an important function in strengthening the civil sphere. They are expected to disseminate accurate information that citizens use to make decisions.

The value of an independent, multifaceted media to the creation and maintenance of civil society is clear. The independent media also serve as watchdogs to ensure that government officials and businesses are held accountable for their actions. Government-run media cannot embody such a role. The independent media are "the most critical of all civil society institutions" because they allow for communication between institutions, CSOs, the government, and the public.

The role of CSOs in the Egyptian society has been recognized as enormous as it played the role of filling the gap between the governments and the Egyptian people, being closer to local, rural communities, CSOs efforts of the development of such communities have been proven over long periods of Egyptian history.

CSOs are modeling a different and clearly an attractive means of social organization that enjoy high public standing and credibility. It is clear that identification with political parties is declining in this country and elsewhere, alongside an increasing alienation from the formal political process. $\left({ }^{22}\right)$

Putnam's research noted a loss of faith in the political system and in the different governments' ability to serve public needs $\left({ }^{23}\right)$. In Egypt, the individual's increasing distrust in governmental institutions as well as the reputation of corruption that marked hundreds of officials in the past four decades, was the driving force that led most average 
Egyptians to direct their charity money (ZAKAH or SADAKAT) to CSOs. The increasing importance of CSOs in Egypt is referred to its dynamic role and its size, estimated to be more than 48 thousand CSOs in Egypt serving over 30 million beneficiaries $\left({ }^{24}\right)$.Such organizations have gained significant importance in Egypt due to its vital role in development and creating bonds between itself and the local and international interest groups, but the sources of funding of CSOs by foreign countries and the interests and intentions of these countries has raised enormous suspicion after the $25^{\text {th }}$ of January 2011 Revolution.

The establishment of numerous private and independent broadcast media facilitated non-profit advertising for Egyptian wide-gap organizations and opened new horizons for Egyptian CSOs to conduct nationwide, creative fund-raising campaigns prior to 2011. Yet, the growth of internet in Egypt, its uses and growing users as well as the accelerated uses of social networks and the power of user-generated content was both an opportunity and a threat for renowned CSOs in Egypt. Accusations, rumors and issues of distrust accumulated numerous challenges to CSOs and created considerable noise to their media messages that immediately and negatively affected the individuals' donations.

The anatomy of the reality of local wide-gap organizations after 2011 suggests a complex crisis scene. The January revolution that toppled Mubarak's regime increased the favorable attitudes towards CSOs, especially those who were not associated with Mubarak's wife or son. Yet, donations dropped immensely in 2011 due to the average citizens' feeling of instability, lack of security, downsizing and closing of numerous business facilities. In 2012, the foreign-funded CSOs case caused considerable damage to the reputation and credibility of CSOs and consequently public donations to these organizations. $\left({ }^{25}\right)$

As the largest majority of such CSOs have had a long history of using religious appeals (Islamic or Christian) in their fund-raising campaigns in traditional and new media, they suffered immensely from a major drop in individuals' donations as a result of the changing 
political orientations and the negative word-of-mouth that tarnished the reputation of numerous popular CSOs in Egypt in 2013.

The long-rooted tradition of many Egyptian wide-gap organizations to use emotional appeals stemming from religious traditions and their use of Islamic rhetoric for fund-raising purposes, lead to the association between these CSOs and religious fanatic and violent movements that suffered increasing resentment from the average Egyptian people after the ousting of Moslem Brotherhood (MB) in 2013. The charity organizations' manipulation of religious appeals proved to be a dangerous strategy with the changing political regimes and orientations.

The breaking point that destroyed the relationship between donators and CSOs came after the June $30^{\text {th }}$ political changes that toppled the Moslem Brotherhood (MB) movement and its president. A court verdict declared $\mathrm{MB}$ a terrorist movement and consequently the new regime confiscated the capital and funds of 1055 CSOs based on their relation to $\mathrm{MB}$ members, among which were well-known CSOs that were accused of using funds collected for social issues to sponsor terrorist attacks against police forces and civilians. Some of those CSOs were officially accused and put under the mandate of the government, like El Gamea ElShareyaa. The rest of the CSOs suffered from the crisis of bad reputation and consequently the drop in individuals' donations that constituted the largest bulk of the budget of these wide-gap organizations, like Resala, Al Orman and Bank El Taam. $\left({ }^{26}\right)$

The relationship between civil society and public relations was highlighted by many scholars. ${ }^{27}$ This research aims at exploring the effect of word-of-mouth WOM and its role in shaping the relationship between the civil society organizations CSOs and the donators in Egypt after 2013.

Numerous research studies investigated varying dimensions of CSOs in Egypt, while few addressed the attitudes towards civil society organizations and their communication activities. As a communication scholar, the measurement of PR activities of CSOs, reputation of CSOs in Egypt, attitudes towards CSOs, and the 
complicated structure of relationships has been my focus in several studies.

The theme of this study suggested the need to review two groups of research studies; the first group that discussed the relationship between media in Egypt and the CSOs and the second group of studies that measured common public attitudes towards CSOs in Egypt.

The first group of studies explored the nature of the relationship between the national, reportorial mass media and the CSOs. The studies revealed that personal communication was more effective than mass media in creating awareness of the CSOs, their strategies and objectives $\left({ }^{28}\right)$. Studies indicated that mass media have a very limited role in creating awareness of the CSOs and promoting their scientific and cultural activities. The influence of mass media to attract volunteers to participate in the activities of the CSOs was very weak. Internet has become the first source of information about CSOs, and then newspapers followed to a less degree by television and friends or family $\left({ }^{29}\right)$. The increasing importance of social media for civil society in creating a public sphere away from the authoritarian regimes and controlled media was recognized by recent studies $\left({ }^{30}\right)$.

The second group of studies explored the attitudes towards CSOS, which are usually a reflection of the organization's activities, good will, credibility, reputation and image and surely the effectiveness of its public relations and communication activities. Numerous studies $\left({ }^{31}\right)$ confirmed the constant positive- attitudes towards CSOs in Egypt until 2013, especially those involved in local community development, social and health care $\left({ }^{32}\right)$. The public positive attitude challenged the governmental media negative coverage of foreignfunded CSOs working in Egypt. $\left({ }^{33}\right)$

Henceforth, this study adopts a new perspective that aims at measuring the effect of WOM on the disturbed relationship between Egyptian general-public donators and wide gap CSOs in Egypt after the drastic change in the Egyptian political regime and orientations in 2013. 


\section{Proposed theory and research questions:}

The WOM model is the framework of this study. It suggests that friends and family as well as people with similar interests are the greatest influencers in the WOM process, which move the recipients from the awareness stage to taking a decision or adopting a behavior. Main factors that affect the WOM process are:

Tie Strength, perceptual affinity, demographic similarity, and source expertise. $\left({ }^{34}\right)$

Tie Strength refers to the closeness of the relationship between two participants in a word of mouth scenario. The better the recipient knows the sender of WOM, the stronger the effect of WOM gets.

Perceptual affinity refers to the likelihood that recipients share similar interests as the sender when receiving new information. Likes, dislikes, interests, groups or affiliations would all go into this category.

Demographic similarity refers to the usual battery of direct marketing statistics including age, marital status, gender, income, children, neighborhood and similar are in this group. Similar to the precise identification of target audience demographics for a more effective media message, WOM works with the same concept for an influencer message.

Source expertise refers to the credibility or believability of a particular source of news. This study applied the variables of the WOM model to the study of donators' attitudes towards local CSOs in Egypt as reflected in the research questions.

\section{Research questions:}

1. What were the sources of credible information about CSOs after 2013 political changes?

2. What is the nature of tie strengths do donors have with senders of WOM?

3. What was the donators' response to the negative WOM about local CSOs after 2013?

4. What was the pattern of donation behavior for local CSOs a) Before June $30^{\text {th }}$ revolution? 
b) After June $30^{\text {th }}$ revolution?

5. What were the reasons for change of donation behavior?

\section{Research design and procedures:}

This is a descriptive study that seeks to collect data, explain and analyze results that lead to the possibility of making generalizations. The research questions seek to assess the effect of WOM on the donation behavior to Egyptian Wide-gap NGOs after June 30, 2013 revolution. The researcher conducted an online-survey on a nonprobability sample from September 2015 to November of the same year. The researcher used Google Forms to create the questionnaire and the link was sent via email to the mailing list of the researcher that includes a variety of professors, professionals, relatives, graduates and senior students.

The choice of personal email instead of social media aimed at assuring the respondents the confidentiality of their responses, identifying the source of the email to them and avoiding the 'spam' notion of facebook questionnaires. The three-month period of the survey was witnessing noticeable polarization of the Egyptian public according to their political views and fluctuation of their trust in CSOs.

The research questions seek to understand three major variables: (1) nature of WOM; (2) donators responses to WOM; (3) patterns of donations to CSOs. WOM was operationalized as the shared judgmental oral statements or audio-visual material about CSOs that were made available to people via personal or social media communication. Nature of WOM is tested on the level of its source and the tie-strength between the sender and the receiver of WOM.

Donators' responses were operationalized as the behavioral reactions to NWOM about well-known CSOs in Egypt during the period of study. These behavioral reactions were measured by the respondents' engagement in EWOM. The ordinal variable scale was used to assess the donators' responses.

Patterns of donations in this research mean the continuity of donations to the trusted wide-gap CSOs before and after June 2013. These 
patterns were tested with a 3-column ratio-scale describing of the regularity of donations before and after June $30^{\text {th }}$ revolution. The results of this section were cross-tabulated with the age groups of the research sample.

The researcher received 120 correct online responses out of 186. The term: 'correct responses' refer to the respondents, who stated that they were affiliated to certain charity organizations as regular donators and/or volunteers. The quantitative study was designed to explore the nature of WOM and its effect on the Egyptian donators' relationship with the CSOs and relative pattern of donation behavior.

Table (1) shows the characteristics of the available sample that answered the online survey. All the respondents were internet users and highly educated, whether they were university students or university graduates, therefore education variable was not included in the table. The imbalance in the gender variable is a result of disqualification of over 47 male respondents, who answered the questionnaire, but were excluded because they were not affiliated to charity organizations in addition to 19 females, who did not meet the survey requirements.

Table 1: Characteristics of research sample

\begin{tabular}{|c|c|c|}
\hline Gender & N & $\%$ \\
\hline Males & 90 & 75 \\
\hline Females & 30 & 25 \\
\hline Total & $\mathbf{1 2 0}$ & $\mathbf{1 0 0 \%}$ \\
\hline
\end{tabular}

\begin{tabular}{|c|c|c|}
\hline Age groups & $\mathrm{N}$ & $\%$ \\
\hline 18-25 Group 1 & 22 & 18.3 \\
\hline 26-40 Group 2 & 61 & 50.8 \\
\hline 41- 55 Group 3 & 29 & 24.2 \\
\hline More than 55 Group 4 & 8 & 6.7 \\
\hline Total & $\mathbf{1 2 0}$ & $\mathbf{1 0 0 \%}$ \\
\hline
\end{tabular}




\section{Research results}

RQ1: What were the sources of credible information about CSOs after 2013 political changes?

The researcher aimed at exploring the sources of credible information about CSOs after 2013 political changes. The analysis of the responses indicated that $70 \%$ of the sample $(\mathrm{N}=84)$ considered the internet (formal online newspapers representing traditional media as well as social networks, especially facebook) the most credible sources of information. Family and friends came second in this category with $24 \%$. Television was ranked last in the respondents' evaluation of the credible sources of information about CSOs after 2013. Radio did not appear on the list (Figure 1).

Figure 1: Sources of information about CSOs

\section{Sources of information about CSOs}

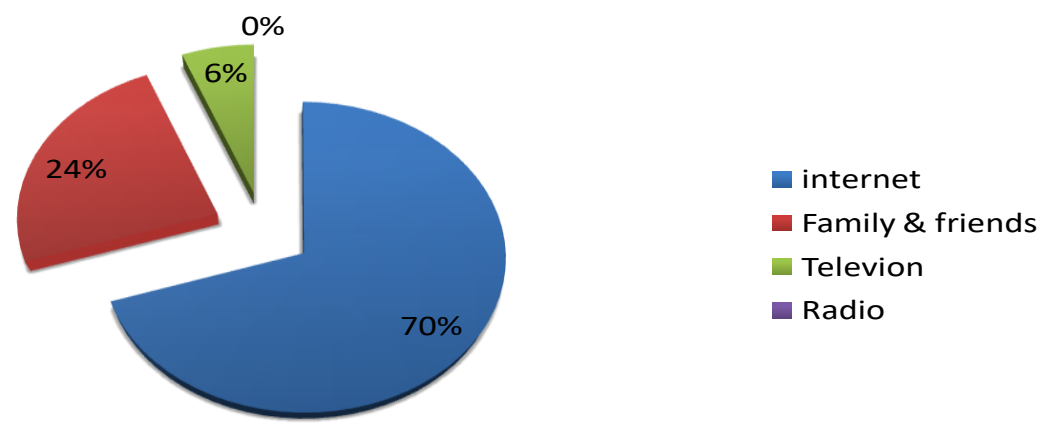

The-above results conforms to the universal trend of media consumption in general; hence the increasing dependence on the internet and the drastic decrease of print media readers $\left({ }^{35}\right)$. Compared to previous studies conducted in Egypt, these results 
contradict with the results of my very first study (Bassyouny, 2009) that ranked informal sources from family or friends as the primary source of information about NGOs (60\%), then came television in the second place with $46 \%$. Internet was not included in that study $\left({ }^{36}\right)$. A more recent study in 2012 showed that the newspapers and internet shared the first place as the main sources of information about NGOs (44\% and $42 \%$ ) with regard to NGOs' foreign-funding case, and then came television in second place and last came family or friends. $\left({ }^{37}\right)$

RQ2: What is the nature of tie strengths do donors have with senders of WOM?

This research explored the nature of tie strengths donors have with senders of WOM. The respondents were asked to rank their main source of information regarding CSOs according to their relationship with that source in order to explore the nature of tie strength between the senders and receivers of WOM. First degree relatives refer to parents, brothers and sisters as well as sons and daughters. Second degree family members may include aunts, uncles and cousins.

Table 2: nature of Tie strengths between senders and receivers of WOM

\begin{tabular}{|c|c|c|c|}
\hline Tie strength & $\mathrm{N}$ & $\%$ & Rank \\
\hline First degree relatives & 9 & $7.5 \%$ & 8 \\
\hline wives/husbands & 2 & $1.7 \%$ & 10 \\
\hline Second degree Family members & 18 & $15 \%$ & 6 \\
\hline Friends & 34 & $28.3 \%$ & 3 \\
\hline Work Colleagues & 42 & $35 \%$ & 2 \\
\hline Facebook friends & 64 & $53.3 \%$ & 1 \\
\hline Media people & 19 & $15.8 \%$ & 5 \\
\hline Governmental officials & 16 & $13.3 \%$ & 7 \\
\hline Social Media influencers & 22 & $18.3 \%$ & 4 \\
\hline Others & 8 & $6.7 \%$ & 9 \\
\hline
\end{tabular}


In the above table, the respondents positioned facebook friends (53\%), work colleagues (35\%) and friends (28.3\%) as the closest, most believed sources of WOM regarding CSOs after 2013 in that order. Social media opinion-leaders occupied fourth place in the list of sources of WOM for the receivers and media people followed. At the end of the list appeared the first degree relatives, strangers, and finally husbands and wives.

Previous studies suggested that people tend to listen more to credible sources, or those that are more trustworthy or have more expertise. Other important factors are the strength of the tie (i.e., friends vs. acquaintances, or strong vs. weak ties) and their similarity to the word-of-mouth recipient. The results of this study confirm the that the WOM from similar others may have a more positive effect. $\left({ }^{38}\right)$

According to the WOM model, this result supports the assumption that perceptual affinity and demographic similarity between the sources and receivers of WOM increase WOM effect on behavior. Nevertheless, the results of the above table do not conform to the assumption that the stronger tie strength between the source and receiver of WOM the stronger its effects become; as friends and colleagues proved to be more influential than family members. Source expertise did not appear as a valid factor in WOM regarding CSOs. The reason may be that that particular period in Egyptian history witnessed considerable citizens' distrust in both governmental spokespeople and their corresponding media outlets on one hand, and the internal and external counterpropaganda against the government with its media channels on the other hand.

RQ3: This research question investigated the donators' recall of and response to the negative WOM about local CSOs after 2013 and the donators' nature of reactions. The researcher offered an open-ended question to identify the donators' recall of the negative eWOM about CSOs.

In their answer to that open-ended question, the respondents stated that they received, through social media, testimonials and footage from citizens, relating few local CSOs with funding the arming of MB militias and offering CSOs premises and facilities for the training of 
those militias. Others mentioned watching videos of Resala ${ }^{39}$ volunteers with their recognizable t-shirts providing food to the citizens in Rabaa' sit-in with a clear suggestion that Resala was supporting the cause of the sit-in with Egyptian donors' money. It is important to differentiate here between the wide-gap CSOs that were officially put under government supervision because of direct relationship with MB (like Al Gameya Al Shariaa Le Ahl AlKitab wal Sunna) and the wide-gap CSOs with rumors about their relationship to MB like Resala and Al Orman.

A quick search of the CSOs online responses and media inserts revealed that there was hardly any online activity of the concerned CSOs to defend themselves and their reputation at that time.

This research question aimed at exploring the nature of the donators' responses to the negative eWOM about CSOs in Egypt after 2013.

Figure 2: level of engagement in eWOM

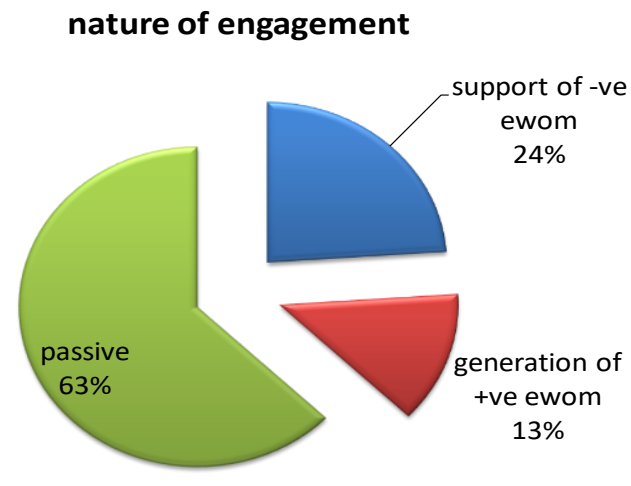

Figure 2 defines the degree and nature of the sample's engagement in WOM regarding local CSOs. Only $24 \%(\mathrm{~N}=29)$ of the sample liked, shared and endorsed such negative material. They were both males and females, between 26-40 years, group 2. 
The odd result was the result of the age group 1, 18-25, as 16 respondents of the 22 members of that age group, stated that they recognized the negative WOM regarding local CSOs, but they did not believe it and they were active in defending those CSOs using comments, sharing personal experiences, and anecdotes that defend the credibility of those charity organizations.

RQ4: What was the pattern of donation behavior for local CSOs

c) Before June $30^{\text {th }}$ revolution?

d) After June $30^{\text {th }}$ revolution?

The survey attempted to explore the patterns of donation behavior for local CSOs before and after the ousting of MB, Rab'aa and Nahda bloody events and the terrorist attacks following the June $30^{\text {th }}$ revolution. Figure 3 indicates the donation patterns of the sample before 2013, while figure 4 shows the changes in those patterns in relation to the different age groups of the sample expressed in Table 1.

Figure 3: Donation patterns before 2013

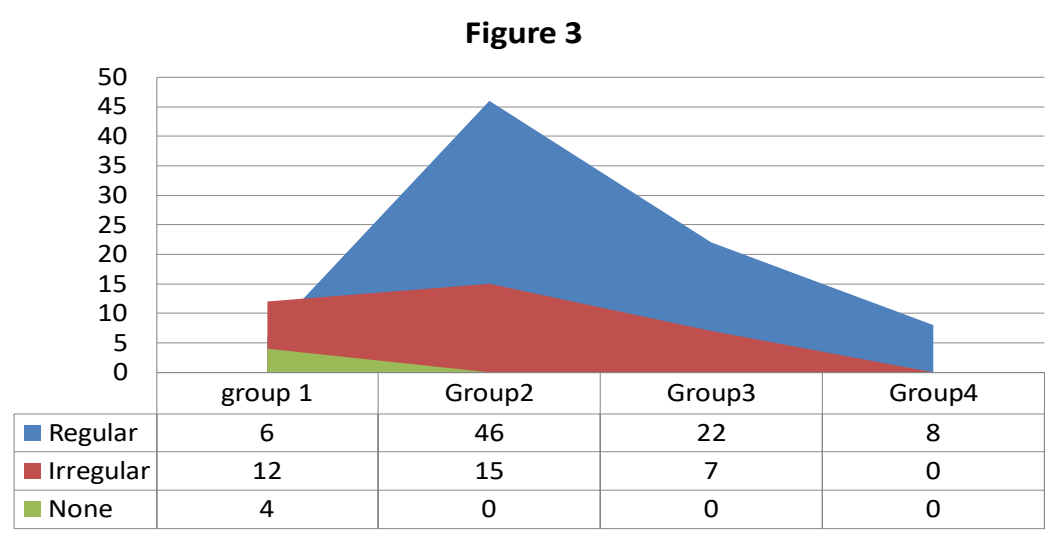

The above figure demonstrates the relationship between the agegroups and their donation behavior before 2013. The age group 2, age between 26 and 40 years, had the highest share of regular donations, 
which means trust in such organizations. Together with group 3, age between 40 and 55, they constituted $57 \%$ of the whole sample $(\mathrm{N}=68)$ with regular donations to local charity organizations. Yet, these statements of the respondents could not be validated with statistics from the CSOs nor from an official source.

The youngest age group 1, from 18 to 25 years, was the least regular donator to the wide-gap charity organizations before 2013. Statistics of internet users in Egypt state the youth to be the heaviest consumers of the internet and social media. $\left({ }^{40}\right)$

Figure 4: Donation patterns after 2013

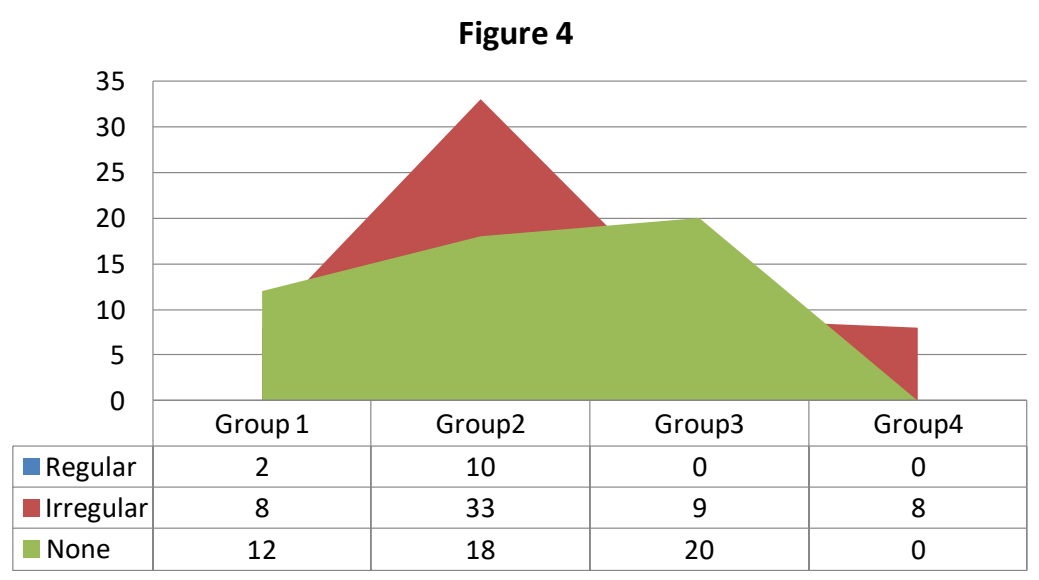

Figure 4 highlights the changes in donations' patterns after 2013 events. It shifted towards irregular donations by $48.3 \%$ of the sample $(\mathrm{N}=58)$ or none by $41.6 \%$ of the survey sample, leaving only $10 \%$ of the sample with regular donations, most of them from age group 2. The results of this research are consistent with a number of online articles that discussed the enormous drop in charity donations to Egyptian CSOs in 2014. 
The researcher admits that this change in the donators' attitudes and donations cannot be exclusively referred to the NWOM effect. There may have been numerous economic and personal factors that lead to the donators' cutting off their regular donations to wide-gap CSOs during the period of study. Therefore the researcher provided the following validating question to investigate reasons for the changing donation behavior after 2013 .

RQ5: What were the reasons for change of donation behavior?

This research intended to investigate reasons for change of donation behavior. Table 3 shows the reasons why Egyptian individual donators refrained from resuming their previous regular donation behavior.

Table 3: Reasons of change of donation behavior

\begin{tabular}{|l|c|c|c|}
\hline \multicolumn{1}{|c|}{ Reason } & No & $\%$ & Order \\
\hline $\begin{array}{l}\text { Conforming with the general trend of the } \\
\text { society at that time }\end{array}$ & 22 & 18.3 & 10 \\
\hline $\begin{array}{l}\text { Negative word-of-mouth about CSOs from } \\
\text { friends and family. }\end{array}$ & 74 & $\mathbf{6 1 . 6}$ & 4 \\
\hline Turbulent economic environment & $\mathbf{1 1 2}$ & $\mathbf{9 3 . 3}$ & $\mathbf{1}$ \\
\hline Negative publicity in mass media & $\mathbf{4 1}$ & $\mathbf{3 4}$ & $\mathbf{7}$ \\
\hline Negative publicity via social media & $\mathbf{5 8}$ & $\mathbf{4 8 . 3}$ & $\mathbf{6}$ \\
\hline $\begin{array}{l}\text { Relatives and acquaintance deserve donations } \\
\text { more than CSOs. }\end{array}$ & $\mathbf{9 5}$ & $\mathbf{7 9}$ & $\mathbf{2}$ \\
\hline Doubts about CSOs spending paths & $\mathbf{3 8}$ & $\mathbf{3 1 . 6}$ & $\mathbf{8}$ \\
\hline Fear of association with any suspicious CSOs & $\mathbf{6 7}$ & $\mathbf{5 5 . 8}$ & $\mathbf{5}$ \\
\hline $\begin{array}{l}\text { Fear of being pursued by security forces and } \\
\text { related to MB }\end{array}$ & $\mathbf{1 6}$ & $\mathbf{1 3 . 3}$ & $\mathbf{9}$ \\
\hline Personal priorities cut donation money & $\mathbf{9 4}$ & $\mathbf{7 8 . 3}$ & $\mathbf{3}$ \\
\hline
\end{tabular}

The respondents were asked to choose more than one answer to the question regarding the reasons for change of their donation behavior, therefore it exceeded the sample size $(\mathrm{N}=120)$ and the total percentage (100). The above table indicates that the majority of respondents 
referred their changing attitude towards CSOs to the turbulent economic environment $(\mathrm{N}=112)$ and personal priorities $(\mathrm{N}=94)$. They found relatives and acquaintance more deserving of donation money and a safer, trusted channel for Zakah (N=95). Wide-gap organizations, the focus of this study, depend heavily on small donations from masses. Therefore, the turbulent economic environment appeared as the first reason for the decreasing donations from average individuals, just like the case of Egyptian's donations in the months following the 2011 January revolution. The terrorist attacks, collapse in stock market, recession in touristic activities of that period caused major economic damages to the macro as well as the micro economy of Egyptians, which was reflected on the amount of donations to charity organizations.

The results of this research emphasize the increasing effect of personal communication and WOM over mass media and electronic word-ofmouth in forming a public opinion against CSOs. $61 \%$ of the sample stated that friends and family were more credible sources of information regarding CSOs than mass or social media. Negative publicity in social media was ranked sixth in the list of reasons, while negative publicity in mass media was ranked as the seventh reason in the list of reasons for reduced donations to local CSOs. A percentage of $55.8 \%$ of the donators expressed their fears to be associated with suspicious CSOs; which confirms that they had negative attitudes towards CSOs in that particular time period. $36 \%$ of the donators clearly referred the reason for freezing donations to their doubts regarding the spending paths of CSOs, which indicates that such donators believed the NWOM and acted accordingly.

\section{Conclusion}

Any research effort to measure the state of civil society, thus, has to take into consideration the peculiar circumstances facing civil society in Egypt today, the dynamics of the time it lives in, and its transforming growth and development. $\left({ }^{41}\right)$

This study explored the effect of WOM on the relationship between the donators and the local wide-gap CSOs in Egypt in the period between 2013 and 2015. Many articles discussed the negative effects 
of the government's decision to suspend and freeze over 1000 CSOs after the ousting of former president Mohamed Morsi, declaration of Moslem Brotherhood as a terrorist entity, freezing liquid assets and suspension of CSOs run by MB members. Suspicion, lack of credibility of donators in all wide-gap CSOs described the relationship between the two parties. The inability of CSOs to engage in a healthy dialogue with donators to defend reputation, allowed the negative WOM to dominate and lead to enormous drop in donation money.

The research questions aimed to understand three major variables: nature of WOM; donators' responses to WOM and corresponding patterns of donations to CSOs before and after 2013.

The results of this study regarding the credible sources of information about CSOs conform to the universal trend of media consumption; hence the increasing dependence on the internet, personal reviews and recommendations from friends, while drastic decrease of dependency on print media.

The WOM model, the framework of this study, suggests that friends and family as well as people with similar interests are the greatest influencers in the WOM process, which move the recipients from the awareness stage to taking a decision or adopting a behavior. Main factors that affect the WOM process are:

Tie Strength, perceptual affinity, demographic similarity, and source expertise.

The results of the first two research questions support the assumption that friends constituted the credible source of information about CSOs more than traditional media and it was proven that internet friends, colleagues and friends were more trusted and closer to believe than family members. The respondents positioned facebook friends (53\%), work colleagues (35\%) and friends (28.3\%) as the closest, most believed sources of WOM regarding CSOs after 2013 in that order, Which confirms the assumptions of the WOM model; namely the stronger the tie between the sender and receivers of WOM, the more it will be believed. Facebook friends and work colleagues share the same perceptual affinity and demographic similarity of the sources and receivers of WOM. The researcher can infer that such conditions 
of the negative WOM regarding CSOs in Egypt lead to the increase WOM effect on behavior, namely the donation behavior of Egyptians during that period. Source expertise did not appear as a valid factor in WOM regarding CSOs. A surprising result showed that $60 \%$ of the respondents' between18-25 was frustrated of the NWOM and they generated PWOM using social media to defend the reputation of CSOs.

While the majority of the sample $(58 \%)$ stated that they were regular donators to local CSOs before 2013, only $12 \%$ declared they remained regular donators after 2013. The respondents referred the change in their donation behavior to the turbulent economic environment and the distrust in the local CSOs. The donators channeled their charity money to closer relatives and acquaintance out of distrust in the credibility of CSOs.

This study explored the dynamics of WOM model and its reflections on the donators'-CSOs relationship. Hence, this study could provide valuable guidelines to CSOs to use pro-active public relations and WOM model as marketing techniques that would create a more beneficial, sustainable and mutual relationships between the two parties.

Future research is needed to further investigate the role of WOM on consumer behavior and its effects on decision- making process. Wide-gap CSOs in Egypt will remain a rich field of study for many more decades, as their role in social, political and economic lives of millions of Egyptians is escalating, despite the crisis situations they face in specific periods of time in Egyptian modern history. 


\section{Endnotes}

${ }^{1}$ )Gauraf, Kumare (2014), "Are social networking more effective than traditional word-of-mouth". In partial fulfillment of the requirement for the degree of Master of Business Administration, Faculty of Management Studies Banaras Hindu University.

$$
\text { ( 2) و ائل على ومينا غالي،"حقوق الانسان، رحلت الانظمة وبقيت الانتهاكات"، المصري اليوم }
$$

$\left({ }^{3}\right)$ Katz, E., \& Lazarfeld, P. F.(1955). Personal Influence. Glencoe, IL: Free Press.

$\left({ }^{4}\right)$ Hong, Soo \& Yang, Sung-Un (2009), "Effects of Reputation, Relational Satisfaction, and Customer-Company Identification on Positive Word-ofMouth Intentions." Journal of Public Relations Research, 21(4):381-403

$\left({ }^{5}\right)$ Ibid, p.398

$\left({ }^{6}\right)$ Gauraf, op. cit., p. 32

$\left({ }^{7}\right)$ Bach Seung B and Soojin Kim (2012), “Online Consumer Complaint Behaviors: The Dynamics of Service Failures, Consumers' Word of Mouth, and Organization-Consumer Relationships," International Journal of Strategic Communication, 6: 59-76.

$\left({ }^{8}\right)$ Gauraf, op.cit., p. 17

$\left({ }^{9}\right.$ ) Hennig-Thurau, Thorsten, Kevin P. Gwinner, Gianfranco Walsh, \& Dwayne D.

Gremler (2004), "Electronic Word-of-Mouth Via Consumer-Opinion Platforms: What Motivates Consumers to Articulate Themselves on the Internet?'Journal of Interactive Marketing, 18 (1), 38-52.

-Jin, Seung-A, Joe Phua (2014), “Following Celebrities' Tweets About Brands: The Impact of Twitter-Based Word-of-Mouth on Consumers 'Source Credibility Perception, Buying Intention, and Social Identification With Celebrities." Journal of Advertising 43(2), 181-195.

$\left({ }^{10}\right)$ Solis, Brian (2011), Engage: The Complete Guide for Brands and Businesses to Build, Cultivate, and Measure Success in the New Web. New York: Wiley.

$\left({ }^{11}\right)$ Chen, Yubo, Scott Fay, and Qi Wang (2011), "The Role of Marketing in Social Media: How Online Consumer Reviews Evolve," Journal of Interactive

Marketing, 25 (2), 85-94.

(12) Jansen, B. J., Zhang, M., Sobel, K., \& Chowdury, A. (2009), "Twitter power: Tweets as electronic word of mouth." Journal of the American Society for Information Science and Technology, 60(11), 2168-2188.

$\left({ }^{13}\right)$ El Gazzar, Nagwa \& Bassyouny Amany(2015)," Trends of Contemporary Research for New Media in Egypt: A Critical Assessment." The Scientific Journal of Public Relations and Advertising Research (3), 1-30.

( ${ }^{14}$ ) http://marketsvoice.com/blog/2015-2016 
$\left({ }^{15}\right)$ Liu, Yong (2006), “Word of Mouth for Movies: Its Dynamics and Impact on Box Office Revenue," Journal of Marketing, 70 (July), 74-89.

$\left({ }^{16}\right)$ Abdel Rahman, Maha (2015), Civil Society Exposed: The Politics of NGOs in Egypt. London; Tauris. Academic Studies.

$\left({ }^{17}\right)$ El-Noury, Dahlia Salah(2005), International Development Donators and Non-governmental Organizations. MA thesis: American University in Cairo.

${ }^{18}$ ___ (2011) "The "Business" of doing Interventions: NGOs, Funders, and Communities," Conference Papers -- International Communication Association. 2011 Annual Meeting, p1-34. 34p.

$\left({ }^{19}\right)$ (2012), 'Ecologies of Information Production: NGOs, Journalism and the Dynamics of Humanitarian and Human Rights News". Conference Papers -- International Communication Association; 2012 Annual Meeting, p1-31, 31p

$\left({ }^{20}\right)$ Bassyouny, Amany (2012), "Media and Public's Attitudes towards CSOs in Egypt: A Case Study of foreign-funded NGOs. " Conference Papers$18^{\text {th }}$ International Conference. Faculty of Mass Communication-Cairo University, p. 1-30.

${ }^{(21)}$ Taylor, M., \& Doerfel, M. L.(2005), “Another dimension to explicating relationships: Measuring inter-organizational linkages." Public Relations Review, 31, 121-129.

(22 )Hewett, Andrew (2004), "How tying funding to 'good behavior' hits critical NGOs." Pacific Journalism Review 10 (1) 2004 p 1-7.

(23) Putnam, R. (2000), Bowling alone: The collapse and revival of American community. New York, NY: Simon and Shuster.

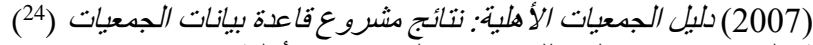
الأهلبة. الطبعة الثانية. القاهرة: الاتحاد العام للجمعيات و المؤسسات مثرات الأهلية.

(25) Bassyouny (2012), op.cit.,p.25

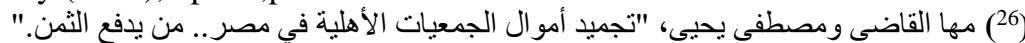

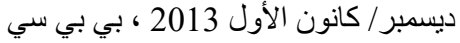

- $\quad$ http://raseef22.com/politics/2015/07/22/egyptian-armed-forces-are-tryingto-make-up-for-the-charitable-role-of-the-brotherhood-associations/

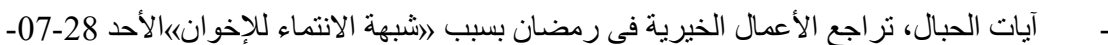
2013

$\left({ }^{27}\right)$ A Discursive Framework for Studying Public Relations in Civil Society, p. 2

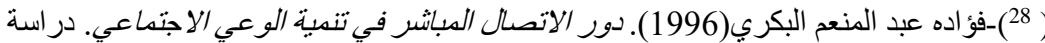

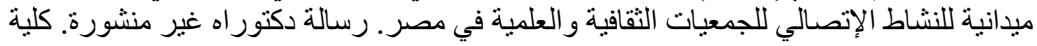

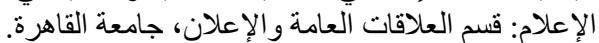


-رشاد أحمد عبد اللطيف(1997) "العو امل المؤثرة على تمويل بر امج الرعاية الاجتماعية بالمؤسسات

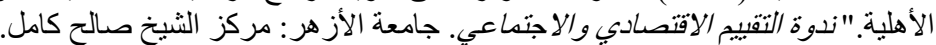

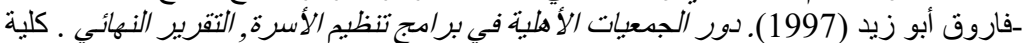
الإعلام: مركز بحوث الر أبي العام.

${ }^{29}$ ) Bassyouny, (2012) ,op.cit., p.25-28

$\left.{ }^{(30}\right)$ Helms, Andrew (2009), "Politics of Information: The Internet and Islamist Politics in Jordan, Morocco and Egypt." Center for Contemporary Arab Studies.

( $\left.{ }^{31}\right)$ Abdel Rahman (2005), op. cit.

(32) El Noury (2005), op. cit.

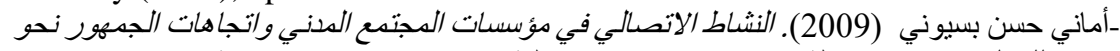

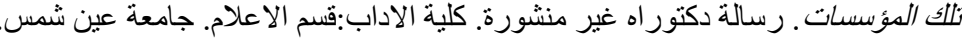

(33) Bassyouny, (2012) op. cit. p. 22-24

${ }^{(34)}$ Model of word of mouth theories of influence. http://widhadh.com/modelof-word-of-mouth-theories-of-influence/ JANUARY 24, 2012 .

(35) Vivian ,John (2013). The Media of Mass communication, $11^{\text {th }}$ Edition, Pearson Educational Inc.

(37 ) Bassyouny,(2012) op.cit.,p.15

$$
\text { (36) (ماني بسيونى (2009)، مرجع سابق، ص } 179
$$

$\left({ }^{38}\right)$ Gauraf, op. cit., p. 32

$\left({ }^{40}\right)$ http://marketsvoice.com/blog/2015-2016

$$
\text { (39) }
$$

$\left({ }^{41}\right)$ "Egypt's Changing Civil Society: The Muslim Brotherhood and New Media" http://www.scribd.com/doc/24176037/Egypt\%E2\%80\%99sChanging-Civil-Society-The-Muslim-Brotherhood-and-New-Media. 